\title{
Management of hydrocele in adolescent patients
}

\author{
Marcello Cimador, Marco Castagnetti and Enrico De Grazia
}

\begin{abstract}
Hydrocele is defined as an abnormal collection of serous fluid in the potential space between the parietal and visceral layers of the tunica vaginalis. In the majority of affected adolescents, hydrocele is acquired and is idiopathic in origin. The pathogenesis of idiopathic hydrocele is thought to be an imbalance in the normal process of fluid production and reabsorption. The diagnosis is usually clinical. Taking a thorough history is essential to rule out any fluctuation in size, which is an indication of a patent processus vaginalis. Scrotal ultrasonography is mandatory in nonpalpable testicles to rule out a subtending testicular solid mass requiring inguinal exploration. Otherwise, open hydrocelectomy via a scrotal incision is the standard treatment of idiopathic hydroceles. The second most common cause of hydrocele in adolescents is varicocelectomy. The risk of hydrocele formation is higher with non-artery-sparing procedures or those performed without microsurgical aid, and in surgery requiring cord dissection. If hydrocele occurs after varicocelectomy, initial management should include observation with or without hydrocele aspiration. Large persistent hydroceles are best served by open hydrocelectomy.
\end{abstract}

Cimador, M. et al. Nat. Rev. Urol. advance online publication 15 June 2010; doi:10.1038/nrurol.2010.80

\section{Introduction}

Hydrocele testis was described as early as the $15^{\text {th }}$ century by Ambroise Pare, and is defined as an abnormal collection of serous fluid in the space between the parietal and visceral layers of the tunica vaginalis, termed the cavum peritoneum scroti. ${ }^{1}$ Hydrocele is the most common cause of painless nonacute scrotal swelling in men. ${ }^{2}$ The normal scrotum has been reported to contain 2-3 $\mathrm{ml}$ of fluid between the tunical layers. Oyen ${ }^{3}$ reported that a limited hydrocele (detectable only by ultrasonography) is found in as many as $65 \%$ of healthy men. Leung et al. ${ }^{4}$ found that $86 \%$ of their subjects, a group of healthy volunteers, had minimal amounts of fluid in one hemiscrotum. The volume at which tunica vaginalis fluid becomes by definition a hydrocele is still a gray area. ${ }^{5}$ Even in cases of an obvious hydrocele, the amount of fluid can be extremely variable between patients and can vary from a small and soft swelling to a large and firm scrotal lump.

In children, the main cause of hydrocele is a congenital patent processus vaginalis, which allows the transfer of fluid between the peritoneal and tunical cavities. Such hydroceles usually resolve by $18-24$ months. ${ }^{6}$ Adult hydroceles are generally acquired and, in the majority of cases, idiopathic in origin. ${ }^{1,2}$ Both etiologies are possible in adolescents; the hydrocele can be caused by a patent processus vaginalis that has remained silent until puberty, or can appear de novo. A history of varicocelectomy or inguinal surgery can also cause the development of a hydrocele. The aim of this Review is to describe

Competing interests

The authors declare no competing interests. the possible etiologies of hydrocele in adolescents, conventionally defined as patients aged between 13 and 18 years, and to discuss the available treatment options for this patient population.

\section{Types of hydrocele}

To ascertain the probability of a hydrocele being either congenital or acquired in relation to patient age, Wilson et al. ${ }^{7}$ retrospectively assessed the presence of a patent processus vaginalis in children who underwent surgical hydrocelectomy (excision of the tunica vaginalis). A noncommunicating hydrocele was observed in $82 \%$ of children over 10 years old and in $86 \%$ of those older than 12 years. The authors observed only one communicating hydrocele in the group of patients older than 12 years, and in this particular individual the history was suggestive of longstanding communication. The authors observed that age at hydrocelectomy was significantly associated with the possibility of having a patent processus vaginalis $(P>0.0001)$ and calculated an odds ratio of 0.783 for each year of life. In other words, the odds of finding a patent processus vaginalis at hydrocele repair were estimated to decrease by a factor of 0.783 per year. Based on this data, one can conclude that unless the clinical history suggests otherwise, all hydroceles in patients older than 12 years should be considered acquired.

In general, the most common type of acquired hydrocele is idiopathic in origin (Box 1). ${ }^{1,2}$ Idiopathic hydroceles are thought to be caused by an imbalance between the secretion and reabsorption of fluid within the closed sac of the tunica vaginalis. ${ }^{8,9}$ Rinker and Allen ${ }^{9}$ reported that patients with a hydrocele also had defective lymphatic
Pediatric Surgical Unit, Department for Mother $\&$ Child Care, University of Palermo, Via Alfonso Giordano 3, 90100 Palermo, Italy (M. Cimador, E. De Grazia). Section of Pediatric Urology, Urology Unit,

Department of Oncological and Surgical Sciences, University Hospital of Padua, Monoblocco Ospedaliero, Via Giustiniani 2, 35128 Padua, Italy (M. Castagnetti).

Correspondence to: M. Cimador mcimador@unipa.it 


\section{Key points}

- Hydrocele in adolescents is most often idiopathic and seldom owing to a persistently patent processus vaginalis

- Varicocelectomy is the second most common cause of hydrocele in adolescents in developed countries; prevalence varies according to surgical technique

- The diagnosis of hydrocele is generally clinical, but idiopathic cases with a nonpalpable testicle should undergo scrotal ultrasonography to rule out a subtending solid testicular mass

- Open hydrocelectomy via scrotal incision is the standard approach for idiopathic hydrocele in adolescents

- Observation should be the initial approach in postvaricocelectomy hydrocele, unless the hydrocele is very large and tense

Box 1 | Types of acquired hydrocele in adolescents

\section{Idiopathic}

Caused by an imbalance between the secretion and reabsorption of fluid in the closed sac of the tunica vaginalis

After varicocelectomy or inguinal surgery

Caused by damage to the lymphatic network during cord dissection

\section{Lymphatic filariasis}

Hydrocele is the most common presenting symptom of patients infected with the mosquito-borne nematode parasite Wuchereria bancrofti

\section{Malignancies}

Hydroceles can occur secondary to cancerous lesions, such as malignant mesothelioma or rhabdomyosarcoma

Intrascrotal infection

Caused by local infection, such as epididymitis

Regional or systemic disease

Hydrocele is associated with a number of viral and nonviral diseases

\section{Abdominal or testicular trauma}

Caused by injury to the scrotum or abdomen

drainage, leading to inadequate reabsorption of serous fluid. Consistently, the protein content of fluid aspirated from idiopathic hydroceles is similar to that of lymphatic fluid. ${ }^{1,9}$ There are no accurate estimates of the incidence of idiopathic hydrocele in adolescents. Pierik et al. ${ }^{10}$ have reported a $3.3 \%$ prevalence of idiopathic hydrocele in a series of infertile men aged 20-58 years who underwent scrotal ultrasound screening.

The second most common cause of scrotal hydrocele in adolescents is varicocelectomy. ${ }^{11-13}$ The hydrocele is thought to be caused by damage to the lymphatic network that drains the testicle during dissection of the spermatic cord. Other procedures that involve cord dissection can also cause the development of hydrocele. For example, Ein et al. ${ }^{14}$ reported five cases of hydrocele formation after pediatric inguinal hernia repair. Hydrocele rate after varicocelectomy is extremely variable ranging from $0 \%$ to $24 \%$ of operated patients, depending on surgical technique. ${ }^{10-13,15-21}$

In developing countries, hydrocele is the most commonly observed chronic presentation of lymphatic
Box 2 | Potential effects of hydrocele on ipsilateral testis

- Increased intrascrotal temperature

- Changes in testicular geometry

- Increased resistivity index of the subcapsular artery

- Absence of testicular diastolic flow

filariasis, ${ }^{22,23}$ a condition that results from infection with the mosquito-borne nematode parasite Wuchereria bancrofti. The infestation, quite uncommon in developed countries, typically presents from adolescence onwards and is estimated to affect over 50 million people in Africa alone, representing an important public health problem in many developing countries. In endemic communities of Africa, the prevalence of hydrocele increases with age and up to $20-30 \%$ of adult males have a hydrocele. ${ }^{22}$

Hydrocele can also occur secondary to a vast array of other testicular conditions (Box 1). ${ }^{24}$ About $50 \%$ of adult patients with a rapidly growing hydrocele are ultimately diagnosed with a malignant mesothelioma of the tunica vaginalis. ${ }^{25}$ This tumor is fairly rare in adolescents, but de Lima et al. ${ }^{26}$ recently reported a case of a 15 -year-old boy with malignant mesothelioma of the tunica vaginalis presenting with clinical signs of hydrocele. ${ }^{26}$ In addition, Zaslau et al. ${ }^{27}$ have reported a rare rhabdomyosarcoma of the tunica vaginalis in an adolescent presenting with hydrocele. Patients with intrascrotal infections, such as epididymitis, regional or systemic diseases, such as Mumps, ${ }^{28}$ or those who have undergone abdominal or testicular trauma can also experience hydroceles. ${ }^{2}$

\section{Clinical consequences of hydrocele}

No data exist on the effects of hydrocele on the testicle in adolescents, but there is evidence in children and adults of raised intrascrotal temperature possibly harming testicular function (Box 2). ${ }^{1}$ Tense hydroceles might also cause a pressure atrophy of the testis. Anatomical changes in testicular morphology, such as the development of fusiform testes, have been observed in infants with large, tense abdominoscrotal hydroceles ${ }^{29}$ and are reportedly reversed after hydrocelectomy. Turgut et al. ${ }^{30}$ reported alterations in testicular geometry in adults, although they observed a tendency for rounding rather than flattening of the ipsilateral testis. ${ }^{30}$ The same authors also documented an increase in resistivity index of the subcapsular artery on the affected side ${ }^{30}$ which might be a sign of ischemia. Nye and Prati, ${ }^{31}$ on the other hand, observed an absent testicular diastolic flow ispilateral to the hydrocele. Hence, early treatment of hydrocele, particularly those that are large and tense, might be necessary to prevent testicular damage. ${ }^{1}$

Hydroceles can also cause discomfort and embarrassment. The latter seems to be directly proportional to the size of the lesion. Studies of lymphatic filariasis endemic communities in coastal villages in southwest Ghana have revealed a negative impact of hydrocele in terms of work performance, sexual functioning, everyday social interaction and relationships. Patients reported major improvements after hydrocelectomy. ${ }^{32}$ 


\section{Clinical presentation and diagnostic work-up}

Patients with hydrocele invariably present with swelling of one or both hemiscrota. In the vast majority of cases, the swelling is asymptomatic. Patients can report a vague sensation of heaviness. Cases of symptomatic hydrocele are usually secondary to trauma, testicular infection or testicular torsion, and should be investigated immediately. The diagnosis of hydrocele is usually clinical, and made by palpation. Transillumination of the hemiscrotum can confirm the diagnosis, although some hydroceles fail to transilluminate owing to thickening of the tunica vaginalis. ${ }^{2}$ In patients from endemic regions, the presence at palpation of lymphangiectasia or a nodular spermatic cord is highly suggestive of filariasis. ${ }^{22,23}$

In adolescent boys, it is essential to take a thorough history in order to distinguish between an acquired hydrocele and a communicating hydrocele caused by a congenital patent processus vaginalis. The major sign of communication is a tendency of the hydrocele to fluctuate in size. Indeed, a communicating hydrocele is typically larger at the end of the day than in the morning, owing to backflow of fluid from the scrotum into the abdominal cavity when the patient lies down. According to Wilson et al. ${ }^{7}$ the presence of communication can be established by both history and physical examination. ${ }^{7}$ The latter includes the ability to reduce hydrocele size by applying manual pressure to the scrotum.

In patients with a previous history of inguinal surgery, it should be noted that hydrocele can occur many years after the initial procedure. In the five cases reported by Ein et al.,${ }^{14}$ surgery was performed between the ages of 2 and 18 months and hydroceles developed at 11-16 years. The most common timing of hydrocele development after varicocelectomy is also unclear. Esposito et al. ${ }^{12}$ reported that hydroceles usually develop during the first few months after surgery (median 2 months), whereas Misseri et al. ${ }^{11}$ state that hydroceles are detected infrequently within the first 6 months after varicocelectomy, and most cases occur after 6 months with some developing after 3 years.

For patients without a clear cause for hydrocele in their history, ultrasonography provides a simple noninvasive imaging tool. Ultrasonography eliminates the need for fluid aspiration, which should be abandoned owing to its invasiveness, the potential hazard of tumor spillage in the event of an occult testis lesion, and the inherent risk of infection. ${ }^{33} \mathrm{~A}$ case of Fournier's gangrene has been reported as a complication of hydrocele aspiration. ${ }^{34}$ Scrotal ultrasonography might be considered unnecessary in patients with an asymptomatic hydrocele but it is, in fact, always recommendable for the possible risk of an incipient, nonpalpable solid testicular mass. In addition, it is absolutely mandatory in patients whose hydrocele is large enough to prevent adequate palpation of the testis. ${ }^{35}$ In patients with filiriasis, ultrasonography can confirm the presence of living adult worms in the lymphatic tracts or lymph nodes. ${ }^{36}$ Ultrasonography might also reveal signs of epididymitis in patients with symptomatic hydrocele. Based on the clinical presentation and previous history, specific additional investigations might be required in these patients, such as urinalysis or voiding cystourethrography.

Additional investigations, such as complex imaging, are not usually required. No grading exists for hydrocele, either clinically or on ultrasonography, which partially limits the comparability of results from different studies, and would perhaps be useful for selecting the most appropriate treatment modality. ${ }^{5}$

\section{Treatment of adolescent hydrocele}

The basic principles of any hydrocele treatment modality are drainage of excessive fluid and prevention of reaccumulation. The easiest way to drain hydrocele fluid is aspiration with a sterile syringe. Fluid reaccumulation can be prevented by eliminating the space between the parietal and visceral layers of the tunica vaginalis with either sclerotherapy or hydrocelectomy. Sclerotherapy involves injection of an inflammatory agent and subsequent adhesion of the two layers of the tunica vaginalis. Surgical hydrocelectomy involves removal of the tunica vaginalis and allows drainage of fluid into the inguinal lymph nodes. If one assumes that the imbalance between fluid production and reabsorption is a temporary phenomenon, active surveillance might become a viable treatment option.

\section{Idiopathic hydrocele}

Surgical hydrocelectomy

No data are available for hydrocelectomy of idiopathic hydrocele in adolescents. However, surgical hydrocelectomy currently represents the gold standard treatment for idiopathic hydrocele in adults. The primary issue regarding hydrocelectomy in adolescents is the ideal surgical approach: should an inguinal approach be favored to rule out the presence of a patent processus vaginalis or rather a scrotal approach be used for improved cosmesis, shortened operative time and elimination of the possibility of ilioinguinal nerve damage during inguinal dissection ${ }^{37}$ Based on the study by Wilson et al., ${ }^{7}$ it can reasonably be concluded that, in children older than 12 years, hydroceles can be repaired through a scrotal incision unless the clinical history is suggestive of communication. Probing the processus at scrotal repair during surgery might further help to confirm the presence of a closed processus vaginalis.

There are three main methods of scrotal hydroceletomy: excision hydrocelectomy, the plication technique and internal drainage of the hydrocele. ${ }^{33}$ Excision hydrocelectomy is performed by removing the tunica vaginalis leaving a $5-10 \mathrm{~mm}$ rim of tissue around the testicle (Figures 1-4). ${ }^{33}$ The procedure is usually performed via a transverse scrotal incision. The intact vaginalis is delivered out of the scrotum, and opened. All fluid is removed and the tunica vaginalis is resected with scissors or electrocautery. Onol et al. ${ }^{38}$ have described a modified technique, using a small $(15 \mathrm{~mm})$ transverse scrotal incision to identify and grasp the tunica vaginalis parietalis. The sac is dissected bluntly under gentle traction and delivered out of the incision. The fully mobilized tunica 

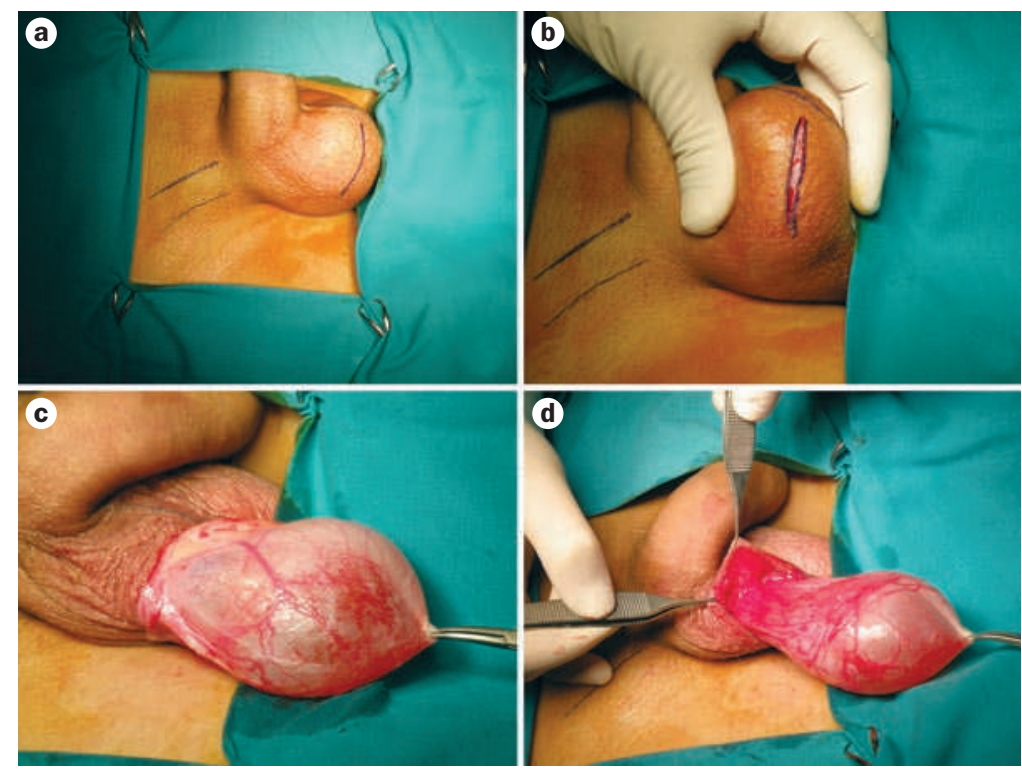

Figure 1 | Excision hydrocelectomy: delivery of the vaginal sac. a | Surgical landmarks such as the spermatic cord and scrotal midline are marked. $\mathbf{b} \mid \mathrm{A}$ transverse scrotal incision is made. $\mathbf{c , d}$ | The vaginal sac is delivered through the incision.
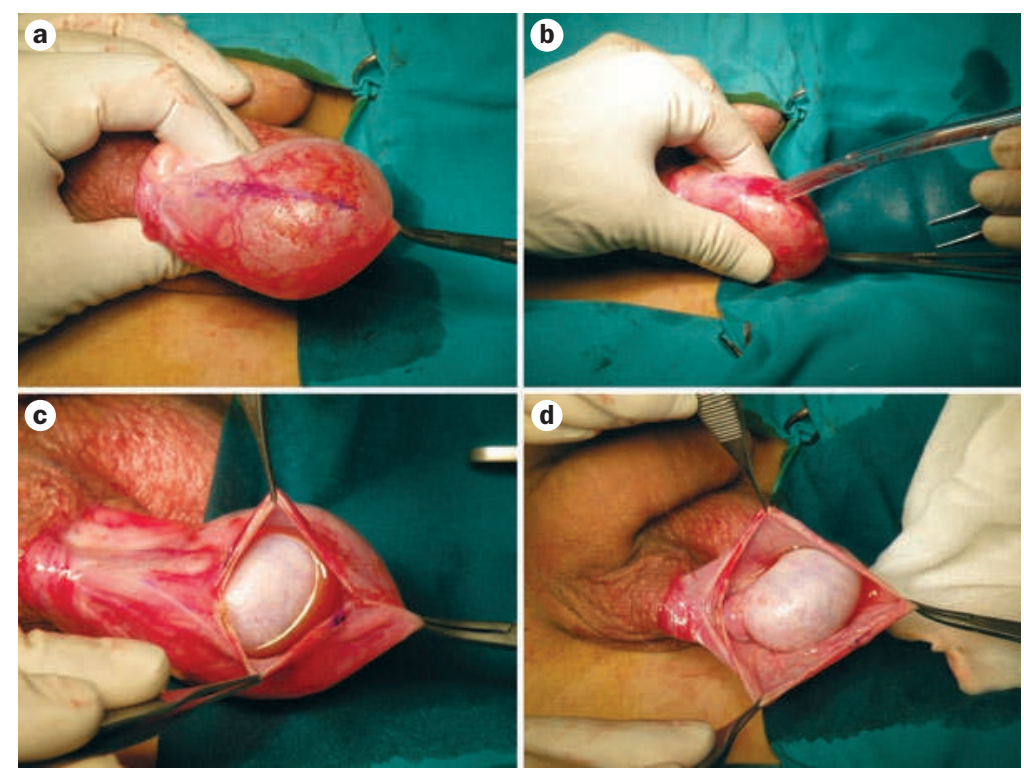

Figure 2 | Excision hydrocelectomy: fluid removal. a | The tunica vaginalis is marked for incision. $\mathbf{b}$ | Aspiration of fluid. $\mathbf{c , d} \mid$ The tunica vaginalis is opened so the testis can be evaluated. the hydrocele, which involves minimal dissection and thus reduced bleeding. ${ }^{42} \mathrm{~A}$ cruciate incision is made in the tunica vaginalis and the edges are folded back and sutured to themselves to create permanent drainage. The window technique, however, is associated with a high hydrocele recurrence rate (85\%) owing to adhesion of the tunica vaginalis causing closure of the window. ${ }^{33}$ To improve the effectiveness of internal drainage, Arslan et al. $^{43}$ have proposed an alternative technique involving insertion of a silicone catheter $15-20 \mathrm{~cm}$ in length, in which holes are made to enable flow of the hydrocele fluid from the parietal layer of the tunica vaginalis to the surrounding scrotal tissue. The authors tested the technique in 45 patients aged 19-67 years with a success rate of $73 \%$. Of course this technique carries the additional concern of introducing a foreign body.

$\mathrm{Ku}$ et al..$^{33}$ assessed 132 patients randomly assigned to one of the three main surgical techniques outlined above, performed by a single surgeon. Excision hydrocelectomy was the most effective technique, but it was also the most morbid with a $75 \%$ rate of postoperative scrotal edema, defined as any degree of scrotal wall swelling with loss of normal rugae. Internal drainage was the least morbid procedure but also the least effective, with an $85 \%$ recurrence rate. The authors therefore concluded that plication hydrocelectomy offers the best cost-to-benefit balance for adult patients.

Finally, as far as complications are concerned, hydrocelectomy is generally considered a safe procedure. Major reported complications include scrotal edema, wound infection, hematoma and recurrence, ${ }^{33,44-46}$ all of which are self-limiting and do not require additional surgery. Recently, however, Hopps and Goldstein ${ }^{47}$ reported a case series of eight men who were found to have iatrogenic injury to the epididymis ${ }^{6}$ or scrotal vas deferens ${ }^{2}$ owing to previous hydrocelectomy. The injury occurred in patients at different ages-some during adolescencebut was discovered as they became adults because it rendered them azoospermic owing to bilaterality or contextual contralateral problems. Hence, it is possible that the rate of unilateral damage might be much higher than expected but such lesions are overlooked because they might never become manifest in the setting of a normal contralateral reproductive tract.

\section{Conservative management and sclerotherapy}

No studies have been performed in adolescents or adults to assess the conservative management of idiopathic hydrocele. In clinical practice, a nonoperative approach might be pursued, as a general principle, until the hydrocele becomes of clinical significance to the patient. Hence, small asymptomatic hydroceles are generally treated with a watch and wait approach. Like its cause, the natural history of the condition remains grossly unknown.

In addition, no studies have been published concerning the use of aspiration plus sclerotherapy in adolescents. A variety of agents have been used in adults, including phenol, anthazoline, ethanolamine oleate, tetradecyl sulfate, tetracycline, and purified mineral talc. ${ }^{48}$ Multiple injections (up to five) might be required 
for cure. ${ }^{49}$ Factors reported to affect the success of sclerotherapy include hydrocele size and wall thickness, with treatment being less effective in large and thick-walled hydroceles. ${ }^{50,51}$ Adverse effects related to the injection are reportedly minimal, but there have been cases of patients requiring orchiectomy owing to an infected hematocele, intense inflammatory reaction or intractable scrotal pain. ${ }^{52-54}$

Studies in adults comparing aspiration plus sclerotherapy to open hydrocelectomy show that aspiration plus sclerotherapy has less complications and morbidity, and is cheaper than open hydrocelectomy, but that it has also a lower success rate and is associated with a lower patient satisfaction than hydrocelectomy. ${ }^{48,49,55}$ In adolescents, aspiration and sclerotherapy is unlikely to gain acceptance owing to the need for often multiple punctures under general anesthesia. Although the available data suggest that sclerotherapy might be a viable option, it has also gained little acceptance among pediatric urologists.

\section{Hydrocele after varicocelectomy \\ Varicocelectomy technique}

Given the assumption that hydrocele formation after varicocelectomy is caused by an iatrogenic lesion to the lymphatic vessels during dissection, it follows that the technique used for varicocelectomy can affect the hydrocele rate. Approaches that avoid dissection of the spermatic cord, such as sclerotherapy of the internal spermatic veins, are associated with virtually no risks of hydrocele formation. ${ }^{19,20}$ Several technical modifcations can be used to prevent damage to the lymphatic vessels during spermatic cord dissection. Optical magnification is generally accepted to be a key component of a lymphatic-sparing varicocelectomy. Accordingly, microsurgical subinguinal varicocelectomy is associated with a very low hydrocele rate, approaching $0 \% \cdot{ }^{15-18,56}$ Optical magnification can also be advantageous for varicocelectomy performed using minimally-invasive surgery. Glassberg et al. ${ }^{57}$ described a laparoscopic lymphaticsparing varicocelectomy technique, which allowed them to significantly reduce the postoperative hydrocele rate compared to the standard laparoscopic procedure, from $11.4 \%$ to $3.4 \%(P=0.025)$.

Lymphatic enhancement with vital dye has been proposed as an additional means of preventing postoperative hydrocele. ${ }^{58}$ Schwentner et al..$^{59}$ compared the occurrence of postoperative hydrocele in 50 adolescents randomly assigned to undergo laparoscopic varicocelectomy with or without isosulfan blue. At 3 months after surgery, the incidence of hydrocele was $0 \%$ and $20 \%$, respectively $(P=0.025)$. In two patients who received isosulfan blue, pigmentation of the left hemiscrotum persisted at 3-month follow-up but resolved by 6 months. Attention should be paid to ensure the dye is injected between the two layers of tunica vaginalis and not into the testis, as the latter is associated with a risk of testicular damage. ${ }^{60}$

Hydrocele rate after varicocelectomy might also be lowered by using techniques that spare the internal spermatic artery, such as high ligation of the
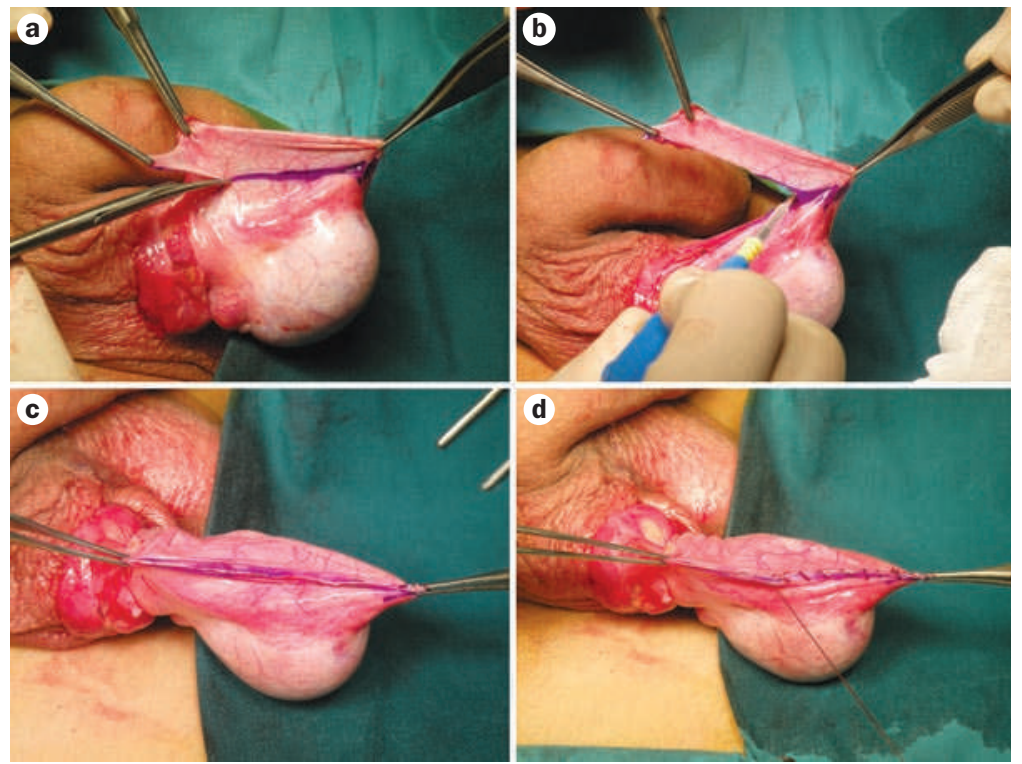

Figure 3 | Excision hydrocelectomy: tunica vaginalis resection. Tissue is removed from the tunica vaginalis with $\mathbf{a} \mid$ scissors or $\mathbf{b} \mid$ electrocautery. $\mathbf{c} \mid$ The edges of residual tunica vaginalis are aligned for the suture. $\mathbf{d} \mid$ The tunica vaginalis is sutured with running $3 / 0$ polyglycolic acid stitches.

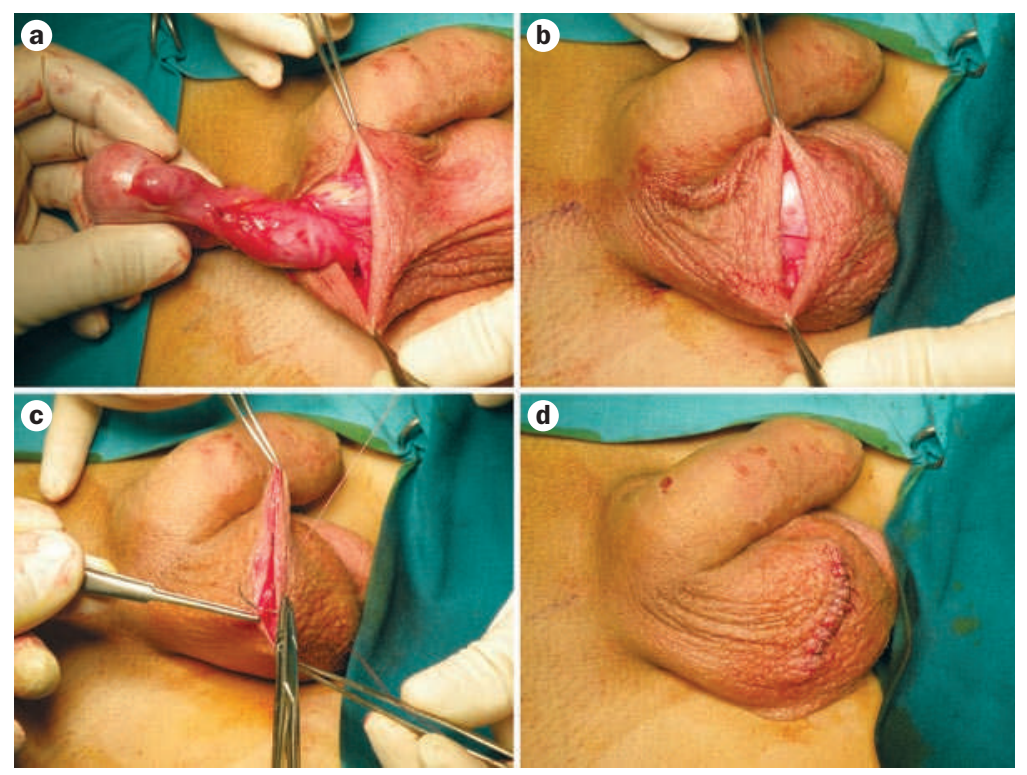

Figure 4 | Excision hydrocelectomy: closing up. a | Final check of the spermatic cord. b,c,d | Multiple layer scrotal suture.

internal spermatic vessels (Palomo procedure). Barroso et al. ${ }^{61}$ performed a systematic review of the literature regarding the Palomo procedure and reported that hydrocele occurred in $3.2 \%$ of patients who underwent artery-sparing surgery and $7.7 \%$ of those who received the classic procedure $(P>0.001)$.

A pre-emptive hydrocelectomy-excision or eversion of the tunica vaginalis at the time of varicocelectomyhas been suggested to reduce the risk of hydrocele formation in patients who undergo varicocelectomy without the aid of microsurgery. ${ }^{62-64}$ Tsikopoulos et al. ${ }^{63}$ compared 15 patients who underwent the Palomo 
procedure plus excision of the tunica vaginalis with 27 patients who underwent the Palomo procedure alone. Postoperative hydrocele requiring surgical treatment was not experienced by any of the patients who underwent a pre-emptive hydrocelectomy, and was observed in four patients who did not. In another study, Castagnetti et al. ${ }^{62}$ compared 96 cases of subinguinal varicocelectomy plus pre-emptive hydrocelectomy with 46 patients who underwent subinguinal varicocelectomy alone. The rate of postoperative hydrocele was statistically lower in those who received a pre-emptive hydrocelectomy ( $4.2 \%$ versus $13 \% ; P=0.04$ ). Pre-emptive surgery can consist of vaginalis excision only or excision and eversion. Hydrocele occurred in 3 of 54 cases where the vaginalis was excised only and in 1 of 42 patients who also underwent eversion. ${ }^{62}$ Hence, vaginalis excision and eversion might be more effective than excision alone. Neither of the series reported any complications associated with pre-emptive excision or eversion of the tunica vaginalis.

\section{Conservative management and aspiration}

Contrary to common practice with regard to idiopathic hydrocele, accumulating evidence suggests that conservative management should be considered the initial approach for hydrocele after varicocelectomy. Esposito et al. ${ }^{12}$ reported the results of a multicenter study on hydrocele management after varicocele surgery; of 34 patients with hydrocele, $47 \%$ were treated with scrotal puncture under local anesthesia leading to hydrocele regression after a median of three punctures (range 1-5); $35.3 \%$ underwent clinical observation and the hydrocele reduced spontaneously within a median of 12 months after its appearance; and $17.7 \%$ were treated with open surgery. In four of the six surgeries, the hydrocele disappeared and in the other two it recurred after surgery and was successfully treated with scrotal puncture. Zampieri et al. ${ }^{65}$ studied 31 patients who developed hydrocele after varicocelectomy. Of these, nine patients required surgical hydrocelectomy after three aspirations, seven had spontaneous resolution of the hydrocele, and 15 were treated with aspiration only. The success rate of aspiration seemed to be related only to the volume of the hydrocele. A volume of $<50 \mathrm{ml}$ per aspiration allowed for spontaneous resolution in $60 \%$ of patients $(P<0.05)$. These studies support the use of aspiration for postvaricocelectomy hydroceles. This procedure seems to be more acceptable for this kind of hydrocele because they are more likely to spontaneously improve.

\section{Treatment of hydrocele in other clinical settings}

Ein et al. ${ }^{14}$ reported five cases of large hydroceles developing after inguinal hernia, suggesting that a persistent patent processus vaginalis is seldom the cause of the hydrocele in this setting. Hence, hydrocelectomy can be performed via the scrotal approach.

Concerning the treatment of filarial-related hydrocele, DeVries $^{22}$ suggests that complete excision of the tunica vaginalis with cauterization and oversuturing of the edges offers the best results. Additionally for this form of hydrocele, but not the others, a vertical incision should be favored over an incision that follows the skin folds in order to preserve the already damaged superficial lymphatics of the skin and subcutaneous tissue.

\section{Conclusions}

The most common form of hydrocele in adolescents is acquired and idiopathic. The diagnosis is usually clinical, but taking an accurate history is essential to rule out any signs of size fluctuation suggestive of a patent processus vaginalis. Preoperatively, a scrotal ultrasound is mandatory whenever the amount of fluid is so abundant to make palpation of the testicle impossible, in order to rule out the presence of a solid mass subtending the hydrocele, in which case an inguinal exploration is required. If there is no solid mass, idiopathic hydroceles should be removed by surgical hydrocelectomy via a scrotal incision. There is no definitive evidence to suggest superiority of tunica vaginalis eversion over excision.

Conservative management of idiopathic hydrocele has not been reported, so the natural history of the condition remains essentially unknown. Likewise, there is no reported experience of sclerotherapy in adolescents, although it has been shown to be a viable alternative to open hydrocelectomy in adults, at least for hydroceles that are neither large nor thick-walled. Sclerotherapy, therefore, deserves further investigation in adolescents.

The risk of hydrocele formation after varicocelectomy is higher for non-artery-sparing techniques, procedures performed without microsurgical support and surgery requiring cord dissection than for the standard approach. If hydrocele occurs after varicocelecetomy, initial management should include observation with or without hydrocele aspiration. This approach is apparently harmless, but its effectiveness seems to be proportional to the size of the hydrocele. Large or persistent hydroceles are therefore best served by surgical hydrocelectomy.

Review criteria
We searched for original research articles focusing
on hydrocele in MEDLINE and PubMed published
between 1990 and 2009 . The search term we used was
"hydrocele". "English", "humans", and "age: adolescent:
13-18 years" were considered as limits. All papers
identified were English-language, full-text papers. We
also searched the reference lists of identified articles for
additional pertinent papers.

1. Wallace, A. F. Aetiology of the idiopathic hydrocele. Br. J. Urol. 32, 79-96 (1969).

2. Rubenstein, R. A., Dogra, V. S., Seftel, A. D. \& Resnick, M. I. Benign intrascrotal lesions. J. Urol. 171, 1765-1772 (2004).

3. Oyen, R. H. Scrotal ultrasound. Eur. Radiol. 12, 19-34 (2002).
4. Leung, M. L., Gooding, G. A. \& Williams, R. D. High-resolution sonography of scrotal contents in asymptomatic subjects. AJR Am. J. Roentgenol. 143, 161-164 (1984).

5. Turgut, A. T. et al. A novel parameter by EFOV US for the quantification and the distinction of physiological amount of scrotal fluid and hydrocele: ratio of testis volume/scrotum volume. Eur. J. Radiol. 63, 414-419 (2007).

6. Christensen, T., Cartwright, P. C., Devries, C. \& Snow, B. W. New onset of hydroceles in boys over 1 year of age. Int. J. Urol. 13, 1425-1427 (2006).

7. Wilson, J. M., Aaronson, D. S., Schrader, R. \& Baskin, L. S. Hydrocele in the pediatric patient: 
inguinal or scrotal approach? J. Urol. 180, 1724-1727 (2008).

8. Ozdilek, S. The pathogenesis of idiopathic hydrocele and a simple operative technique. J. Urol. 77, 282-284 (1957).

9. Rinker, J. R. \& Allen, L. A lymphatic defect in hydrocele. Am. Surg. 17, 681-686 (1951).

10. Pierik, F. H., Dohle, G. R., van Muiswinkel, J. M., Vreeburg, J. T. \& Weber, R. F. Is routine scrotal ultrasound advantageous in infertile men? J. Urol. 162, 1618-1620 (1999).

11. Misseri, R., Gershbein, A. B., Horowitz, M. \& Glassberg, K. I. The adolescent varicocele. II: the incidence of hydrocele and delayed recurrent varicocele after varicocelectomy in a long-term follow-up. BJU Int. 87, 494-498 (2001).

12. Esposito, C. et al. Incidence and management of hydrocele following varicocele surgery in children. J. Urol. 171, 1271-1273 (2004).

13. Hassan, J. M., Adams, M. C., Pope, J. C. $4^{\text {th }}$, Demarco, R. T. \& Brock, J. W. $3^{\text {rd }}$. Hydrocele formation following laparoscopic varicocelectomy. J. Urol. 175, 1076-1079 (2006)

14. Ein, S. H., Nasr, A., Wales, P. \& Gerstle, T. The very large recurrent postoperative scrotal hydrocele after pediatric inguinal hernia repair: a rare problem. Pediatr. Surg. Int. 25, 239-241 (2009)

15. Lemack, G. E., Uzzo, R. G., Schlegel, P. N. \& Goldstein, M. Microsurgical repair of the adolescent varicocele. J. Urol. 160, 179-181 (1998).

16. Minevich, E., Wacksman, J., Lewis, A. G. \& Sheldon, C. A. Inguinal microsurgical varicocelectomy in the adolescent: technique and preliminary results. J. Urol. 159, 1022-1024 (1998)

17. Cayan, S., Acar, D., Ulger, S. \& Akbay, E. Adolescent varicocele repair: long-term results and comparison of surgical techniques according to optical magnification use in 100 cases at a single university hospital. J. Urol. 174, 2003-2006 (2005).

18. Yaman, O., Soygur, T., Zumrutbas, A. E. \& Resorlu, B. Results of microsurgical subinguinal varicocelectomy in children and adolescents. Urology 68, 410-412 (2006).

19. Zaupa, P., Mayr, J. \& Höllwarth, M. E. Antegrade scrotal sclerotherapy for treating primary varicocele in children. BJU Int. 97, 809-812 (2006).

20. Beutner, S. et al. Treatment of varicocele with reference to age: a retrospective comparison of three minimally invasive procedures. Surg. Endosc. 21, 61-65 (2007).

21. Diamond, D. A. et al. Varicocele surgery: a decade's experience at a children's hospital BJU Int. 104, 246-249 (2009).

22. DeVries, C. R. The role of the urologist in the treatment and elimination of lymphatic filariasis worldwide. BJU Int. 89 (Suppl. 1), 37-43 (2002).

23. Noroes, J. et al. Pathogenesis of filarial hydrocele: risk associated with intrascrotal nodules caused by death of adult Wuchereria bancrofti. Trans. R. Soc. Trop. Med. Hyg. 97 561-566 (2003)

24. Taskinen, S., Fagerholm, R., Aronniemi, J., Rintala, R. \& Taskinen, M. Testicular tumors in children and adolescents. J. Pediatr. Urol. 4, 134-137 (2008)

25. Wolanske, K. \& Nino-Murcia, M. Malignant mesothelioma of the tunica vaginalis testis: atypical sonographic appearance. J. Ultrasound Med. 20, 69-72 (2001).

26. de Lima, G. R. et al. A rare case of malignant hydrocele in a young patient. J. Pediatr. Urol. 5 , 243-245 (2009).
27. Zaslau, S., Perlmutter, A. E., FarivarMohseni, H., Chang, W. W. \& Kandzari, S. J. Rhabdomyosarcoma of tunica vaginalis masquerading as hydrocele. Urology 65, 1001 (2005).

28. Tarantino, L., Giorgio, A., de Stefano, G. \& Farella, N. Echo color Doppler findings in postpubertal mumps epididymo-orchitis. J. Ultrasound Med. 20, 1189-1195 (2001).

29. Cozzi, D. A. et al. Infantile abdominoscrotal hydrocele: a not so benign condition. J. Urol. 180, 2611-2615 (2008)

30. Turgut, A. T. et al. Unilateral idiopathic hydrocele has a substantial effect on the ipsilateral testicular geometry and resistivity indices. J. Ultrasound Med. 25, 837-843 (2006).

31. Nye, P. J. \& Prati, R. C. Jr. Idiopathic hydrocele and absent testicular diastolic flow. J. Clin. Ultrasound 25, 43-46 (1997).

32. Ahorlu, C. K., Dunyo, S. K., Asamoah, G. \& Simonsen, P. E. Consequences of hydrocele and the benefits of hydrocelectomy: a qualitative study in lymphatic filariasis endemic communities on the coast of Ghana. Acta Trop. 80, 215-221 (2001).

33. Ku, J. H., Kim, M. E., Lee, N. K. \& Park, Y. H The excisional, plication and internal drainage techniques: a comparison of the results for idiopathic hydrocele. BJU Int. 87, 82-84 (2001).

34. Ali, M. Z. Fournier's gangrene-a rare complication of hydrocele aspiration. J. Coll. Physicians Surg. Pak. 14, 304-305 (2004).

35. Horstman, W. G. Scrotal imaging. Urol. Clin. North Am. 24, 653-671 (1997).

36. Norões, J. et al. Ultrasonographic evidence of abnormal lymphatic vessels in young men with adult Wuchereria bancrofti infection in the scrotal area. J. Urol. 156, 409-412 (1996).

37. Bassel, Y. S., Scherz, H. C. \& Kirsch, A. J. Scrotal incision for undescended testes with or without a patent processus vaginalis. J. Urol. 177, 1516-1518 (2007)

38. Onol, S. Y. et al. A novel pull-through technique for the surgical management of idiopathic hydrocele. J. Urol. 181, 1201-1205 (2009).

39. Lord, P. H. A bloodless operation for the radical cure of idiopathic hydrocele. Br. J. Surg. 51, 914-916 (1964).

40. Singh, D. R., Gupta, S. K. \& Gupta, S. Lord's procedure: a curative outpatient operation for primary hydrocele. J. Indian Med. Assoc. 94 , 141-142 (1996)

41. Shah, P. A., Dewoolkar, V. V. \& Changlani, T. T. Ambulatory hydrocele surgery: a review of 50 cases. J. R. Coll. Surg. Edinb. 37, 385-386 (1992).

42. Nigam, V. K. Window operation: new technique for hydrocele. Urology 24, 481-482 (1984).

43. Arslan, M., Kilinç, M., Yilmaz, K. \& Oztürk, A A new approach in the management of the hydrocele with a silicone catheter. Urology 63, 170-173 (2004).

44. Rodriguez, W. C., Rodriguez, D. D. \& Fortuno, R. F. The operative treatment of hydrocele: a comparison of 4 basic techniques. J. Urol. 125, 804-805 (1981).

45. Albrecht, W., Höltl, W. \& Aharinejad, S. Lord's procedure-the best operation for hydrocele? Br. J. Urol. 68, 187-189 (1991).

46. Kiddoo, D. A., Wollin, T. A. \& Mador, D. R. A population based assessment of complications following outpatient hydrocelectomy and spermatocelectomy. J. Urol. 171, 746-748 (2004).

47. Hopps, C. V. \& Goldstein, M. Microsurgical reconstruction of iatrogenic injuries to the epididymis from hydrocelectomy. J. Urol. 176, 2077-2079 (2006).

48. Beiko, D. T., Kim, D. \& Morales, A. Aspiration and sclerotherapy versus hydrocelectomy for treatment of hydroceles. Urology 61, 708-712 (2003).

49. Shan, C. J., Lucon, A. M. \& Arap, S. Comparative study of sclerotherapy with phenol and surgical treatment for hydrocele. J. Urol. 169, 1056-1059 (2003).

50. Fracchia, J. A., Armenakas, N. A. \& Kohan, A. D. Cost-effective hydrocele ablation. J. Urol. 159, 864-867 (1998).

51. Musa, M. T., Fahal, A. H. \& el Arabi, Y. E. Aspiration sclerotherapy for hydroceles in the tropics. Br. J. Urol. 76, 488-490 (1995).

52. Bullock, N. \& Thurston, A. V. Tetracycline sclerotherapy for hydroceles and epididymal cysts. Br. J. Urol. 59, 340-342 (1987).

53. Stattin, P., Karlberg, L. \& Damber, J. E. Long-term outcome of patients treated for hydrocele with the sclerosant agent sodium tetradecyl sulphate. Scand. J. Urol. Nephrol. 30, 109-113 (1996).

54. Badenoch, D. F., Fowler, C. G., Jenkins, B. J., Roberts, J. V. \& Tiptaft, R. C. Aspiration and instillation of tetracyline in the treatment of testicular hydrocele. Br. J. Urol. 59, 172-173 (1987)

55. Khaniya, S., Agrawal, C. S., Koirala, R., Regmi, R. \& Adhikary, S. Comparison of aspirationsclerotherapy with hydrocelectomy in the management of hydrocele: a prospective randomized study. Int. J. Surg. 7, 392-395 (2009).

56. Van der Brink, B. A., Palmer, L. S., Gitlin, J., Levitt, S. B. \& Franco, I. Lymphatic-sparing laparoscopic varicocelectomy versus microscopic varicocelectomy: is there a difference? Urology 70, 1207-1210 (2007).

57. Glassberg, K. I., Poon, S. A., Gjertson, C. K. DeCastro, G. J. \& Misseri, R. Laparoscopic lymphatic sparing varicocelectomy in adolescents. J. Urol. 180, 326-330 (2008).

58. Oswald, J., Körner, I. \& Riccabona, M. The use of isosulphan blue to identify lymphatic vessels in high retroperitoneal ligation of adolescent varicocele-avoiding postoperative hydrocele. BJU Int. 87, 502-504 (2001).

59. Schwentner, C. et al. Laparoscopic varicocele ligation in children and adolescents using isosulphan blue: a prospective randomized trial. BJU Int. 98, 861-865 (2006).

60. Makari, J. H. et al. Safety and efficacy of intratesticular injection of vital dyes for lymphatic preservation during varicocelectomy. J. Urol. 178, 1026-1030 (2007).

61. Barroso, U. Jr, Andrade, D. M., Novaes, H., Netto, J. M. \& Andrade, J. Surgical treatment of varicocele in children with open and laparoscopic Palomo technique: a systematic review of the literature. J. Urol. 181, 2724-2728 (2009).

62. Castagnetti, M., Cimador, M., DiPace, M. R., Catalano, P. \& De Grazia, E. 'Preemptive hydrocelectomy' in subinguinal varicocelectomy. Urol. Int. 81, 14-16 (2008).

63. Tsikopoulos, G. K., Roussis, X. S., Georgakis, J., Papouis, G. \& Tryfonas, G. J. Does incision of the tunica vaginalis during the Palomo procedure prevent post-operative hydrocele? Br. J. Urol. 81, 612-613 (1998)

64. Castagnetti, M. et al. Evolving management of adolescent varicocele. J. Pediatr. Urol. 4 , 107-112 (2008).

65. Zampieri, N., El-Dalati, G., Ottolenghi, A. \& Camoglio, F. S. Percutaneous aspiration for hydroceles after varicocelectomy. Urology 74, 1122-1124 (2009). 